\author{
Military Technical College \\ Kobry El-Kobba, \\ Cairo, Egypt
}

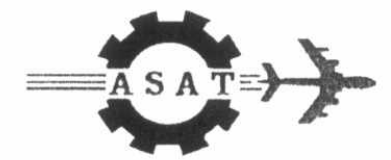

11-th International Conference

on Aerospace Sciences \&

Aviation Technology

\title{
EXPERIMENTAL INVESTIGATION ON CONTROLLING OF MUZZLE BLAST WAVE IN AUTOMATIC SMALL ARMS
}

\author{
M. A. Moghazy*
}

\begin{abstract}
Muzzle blast wave in small arms represents special problems for many applications. They may be attributed to supersonic flow of the discharged propellant gases from the barrel muzzle after the projectile departure. Herein, experimental investigation of controlled and uncontrolled blast wave has been carried out under different working and design parameters. Different silencer design theories were carried out, to control the blast wave in both subsonic and supersonic cases, which produced from automatic small arms. The pressure-time history of gases discharging from an automatic rifle 7.62 x 39-mm was measured for different mass of propellants. In addition, recoil force for the rifle without as well as with silencer and the projectile muzzle velocity has been measured. Results showed that, for different mass of propellants in ammunition and suitable design of silencer, the sounds could be reduced by about 90 percent. In addition, silencers reduced recoil energy by about 20 percent. Also, the silencer efficiency increases by decreasing blast wave pressure as well as mass of propellant of ammunition decreasing.
\end{abstract}

\section{KEY WORDS}

Supersonic Flow, Blast-Waves, Discharging of Gases, Automatic Small Arms, Pressure Wave and Silencer Performance.

\section{INTRODUCTION}

The silencer modifies the weapon firing signature by containing or catching the muzzle blast wave's influence in a box equipped with ports, etc...[1]. Most silencers had been designed empirically [2].

Sound field is interpreted due to two main parameters; the first parameter is owing to effect of pressure wave and pressure difference behind projectile at exit moment, while the second parameter is related to the sound produced by the velocity of the flying projectile. There is no technology which can remove the sound of a supersonic projectile, no matter what claims are made to the contrary.

*Egyptian Armed Forces. 
The blast wave initially constrains the free-flow expansion until it decouples from the flow fields. Generally, the muzzle flow fields of a weapon exhibit the structure of a supersonic, under expanded jet flow encapsulated by the outer blast wave. Because of the high in-bore gas pressure, the jet flow rapidly exits from the barrel muzzle and, in the early stages, is severely impeded by the blast wave, since the blast and jet flow strongly interact $[3,4]$.

Various numerical solutions have been reported in the past decade for different muzzleblast cases [5-8]. Yet the propagation and decay of the high-pressure waves of muzzle blast depend on the internal flow of gases. Herein, a reliable silencer was designed to control the produced blast wave from automatic small arms.

As mentioned before, the overall purpose in the present study is to from experimental work. Finally, conclusions are obtained in the course of the present study.

\section{EXPERIMENTAL WORK AND DISCUSSION}

The main objective of experimental work is to determine the silencer performance. The test rig consists of automatic rifle $7.62 \times 39(\mathrm{~mm})$, Blast and Vibration Monitoring, "Nitro Consult" UVS which has been used for measuring and recording the pressure wave of gases in order to clarify the mechanism of the generation of blast wave. In addition to the muzzle velocity measuring device was used for measuring the projectile muzzle velocity and force transducer for measuring recoil force.

Schematic views of experimental setup of the instruments are shown in figures $(1,2)$. For obtaining good results, many experimental parameters were carried out, to control the blast wave in both subsonic and supersonic cases, which produced from automatic small arms.

The construction and dimensions of designed silencer are shown in Fig. (4). One could be notice that:-

- Silencer has rubber disks and metal dishes for maximum control of blast wave of gases.

- The distributions of nozzles in inner components of silencer would eliminate a great part of gases energy.

- The distributions of nozzles on outer cylinder of silencer would give a good effect in decreasing of rifle recoil.

To achieve these requirements, a silencer had been manufactured. The metal used for silencer is aluminium, which is tough and very durable. It takes non-reflective surfaces and holds paint very well.

To measure the performance of the silencer for different propellant masses, the ammunition used in different tests was prepared.

To realize the above mentioned requirements, the following measurements have been carried out:-

a. Projectile Muzzle Velocity.

b. Pressure of Blast Wave of Gases. 
c. Recoil of Rifle Without \& With Silencer.

d. Silencer Efficiency.

All above measurements were carried out in the same time. These iterations have been conducted with experimental work for giving a good investigation of silencer performance as possible.

\section{a. Projectile Muzzle Velocity}

Measurement of the projectile muzzle velocity were mainly concerned for different propellant charge masses from $\omega_{1}=0.8(\mathrm{gm})$ up to $\omega_{11}=1.8(\mathrm{gm})$. For measuring the projectile muzzle velocity, the muzzle measuring velocity was used and it puts at $X=3$ [m] from the rifle muzzle. To investigate the effect of the propellant charge mass on the silencer performance, the normal ammunition $7.62 \times 39 \mathrm{~mm}$ was used. The Variation of projectile muzzle velocity with propellant charge mass is shown in Table 1.

Table 1. Variation of projectile muzzle velocity with propellant charge mass

\begin{tabular}{|l|c|c|c|c|c|c|c|c|c|c|c|}
\hline Charges & $\omega_{1}$ & $\omega_{2}$ & $\omega_{3}$ & $\omega_{4}$ & $\omega_{5}$ & $\omega_{6}$ & $\omega_{7}$ & $\omega_{8}$ & $\omega_{9}$ & $\omega_{10}$ & $\omega_{11}$ \\
\hline $\begin{array}{l}\text { Propellant } \\
\text { Mass (gm) }\end{array}$ & 0.8 & 0.9 & 1 & 1.1 & 1.2 & 1.3 & 1.4 & 1.5 & 1.6 & 1.7 & 1.8 \\
\hline $\begin{array}{l}\text { Muzzle Velocity } \\
\text { (m/s) }\end{array}$ & 300 & 345 & 390 & 425 & 470 & 510 & 550 & 600 & 650 & 700 & 730 \\
\hline
\end{tabular}

\section{b. Pressure of Blast Wave of Gases}

For measuring the pressure wave of gases after the projectile departure from the barrel muzzle, analyzer named Blast and Vibration Monitoring was used.

Blast and Vibration Monitoring was put at axial distance from the barrel muzzle $(x=2$ $(\mathrm{m}))$ and radial distance $(y=1(\mathrm{~m}))$ from the barrel muzzle of the rifle, as in Fig. (2). The results were reported at the instant at which the projectile departure from the barrel muzzle.

Figures (5-7) show the pressure -time history measured for the rifle without silencer after projectile departure from the barrel muzzle and mass of propellant, $\omega=1.8-1.6$ (gm).

For automatic rifle, equipped with the silencer, after projectile departure from the barrel muzzle and mass of propellant, $(\omega=1.8(\mathrm{gm})$ to $\omega=1.6(\mathrm{gm}))$, the pressure -time history was measured for blast wave of gases, (figures (8-10)). 
From the instant of firing, the additional action period continues for nearly 10 (ms) until the pressure in the extension part drops to ambient value.

The results were showed in figures (5-10):

1- As the projectile leaves the muzzle, the pressure inside the combustion chamber quickly decreases. On the other hand, the pressure at the muzzle exit jumps marking the instant of start of additional action of gases.

2- The instantaneous pressure at the muzzle exit is showing the over pressure of gases in additional action period, caused by the free air blast wave and ground refection.

3- The pressure drop due to using silencer was reached about $90 \%$.

4- Maximum pressures or peak pressures decreases by decreasing the mass of propellant from $\omega=0.8(\mathrm{gm})$ up to $\omega=1.8(\mathrm{gm})$.

\section{c. Recoil of Rifle without \& with Silencer}

Figures $(11,12)$ show that, peak of recoil forces (without and with muzzle brake) were decreased from $1.0188[\mathrm{KN}]$ to $849[\mathrm{~N}]$, silencer reduced recoil force by about 20 percent. Integrating the recoil force-time history on the dynamic signal analyzer, the recoil impulse may be calculated as:-

$$
\mathrm{I}=\int_{0}^{t} F \mathrm{~d} \mathrm{t}
$$

In the same time, recoil velocity of the rifle was computed by applying the recoil impulse-time history in the momentum equation of recoiling parts on the Dynamic Signal Analyzer.

In Fig. 13, one could compare between the recoil velocity-time history for the rifle and rifle equipped with the latest muzzle brake of the third group. Recoil velocity was found to be decreased from $1.32455(\mathrm{~m} / \mathrm{s})$ to $1.06(\mathrm{~m} / \mathrm{s})$. Herein, silencer could reduce recoil velocity by about 20 percent, or it may be as much as muzzle brakes.

\section{d. Silencer Efficiency.}

Sound field is interpreted due to two main parameters; the first parameter is owing to effect of pressure wave, while the second parameter is related to the sound produced by the velocity of the flying projectile [9]. There is no technology which can remove the sound of a supersonic projectile, no matter. Then, the silencer efficiency could be represented only by impulse of gases. The silencer performance could be obtained by dividing the difference of the intensity of gases without and with silencer on the intensity of gases without silencer as follows:-

$$
\beta=\left(I_{0}-I_{S}\right) / I_{0}
$$


where $I_{0}$ and $I_{S}$ is the intensity of gases without and with silencer consequently and $\beta$ is the silencer performance, equation (2) could be written as:

$$
\beta=1-\left(p_{s} / p\right)^{2}
$$

where

$$
\mathrm{I}=\mathrm{p}^{2} /(\text { o.c) }
$$

$\mathrm{p}$ and $\mathrm{p}_{\mathrm{S}}$ are the pressure of blast wave of gases without and with silencer consequently, $\rho$ is the gases density and $c$ is the speed of sound in air. When applied the experimental results in equation [3], it could be noticed that, by decreasing the value of pressure of blast wave of gases, when using silencer, the silencer efficiency increases. The pressure of gases and projectile muzzle velocity are decreased by decreasing mass of propellant from $\omega=1.8(\mathrm{gm})$ to $\omega=0.8(\mathrm{gm})$.

\section{CONCLUSIONS}

After firing and projectile departure from the barrel muzzle, the blast waves or pressure waves are produced by the rapid discharging of gases to air. Silencers did not have any notable adverse effect on shooting accuracy. Silencers hide the muzzle flash and effectively prevent the movement of foliage, grass or twigs and puffs of sand. An experimental work was carried out to get new insight on silencer performance. Experimental investigation of controlled and uncontrolled blast wave has been carried out under different working and design parameters. In this work, for obtaining good results, reliable silencer was designed to control the blast wave in both subsonic and supersonic cases, which produced from automatic small arms.

The reliable silencer was involved, in distributions of nozzles in both inner components of silencer, eliminate a great part of gases energy and on outer cylinder of silencer have a good effect in decreasing of rifle recoil. In addition, for maximum control of blast wave of gases rubber disks and metal dishes were put in manufactured silencer.

Results showed that, for different mass of propellants in ammunition and suitable design of silencer, the sounds could be reduced by about 90 percent by means of designed silencer. In addition, Silencers reduced recoil energy by about 20 percent, as much as muzzle brakes. The silencer efficiency increases by decreasing blast wave pressure or mass of propellant of ammunition. 


\section{REFERENCES}

[1] Erodes, J. I. and Del Guidice, P. D. "Calculation of Muzzle Blast Flow fields," AIAA J, VOL.13, NO. 8, August 1975, pp. 1048-1055.

[2] Taylor, T. D. and Lin, T. C. "Numerical model for Muzzle Blast Flow Field," AIAA J., VOL.19, NO. 3, March 1981, pp. 346-34.

[3] Fans ler, K.S. and schmidt, E.M. The Relation ship between interior Ballistics, Gun exhaust parameters, and muzzle blast overpressure, "AIAA paper 82-0856, June 1982.

[4] Text book of ballistics and gunnery, part I: Basic theory Vol. I, tier Majesty's london, 1987.

[5] White, F. M., "Viscous Fluid Flow", 2nd Edn. McGraw- Hill Book Company, New York, 1991.

[6] Klingenberg, G.and Joseph, M. Heimerl "Gun Muzzle Blast and Flash," American Institute of Aeronautics and Astronautics, U.S.A. Washington, 1995.

[7] Patrick H., William E. Carscallen, "Compressible Fluid Flow", McGraw- Hill, New York, 1997.

[8] Boisson, and D. Cayzac, R. "Study of the Gas Discharge Occurring in a Gun Barrel after the Projectile departure, Leave the Barrel-Validation for the 30 $\mathrm{mm}$ Gun", 18th International Symposium Ballistic, San Antonio, TX, U. S. A., 15-19 November, 1999.

[9] Aboel-Khair, M. S. and Sherief, H. A. S. "Control Over Blast Wave at Exit point of View of Super-Sonic Projectile", Mechanical Conference, M. T. C., Cairo, 2001. 


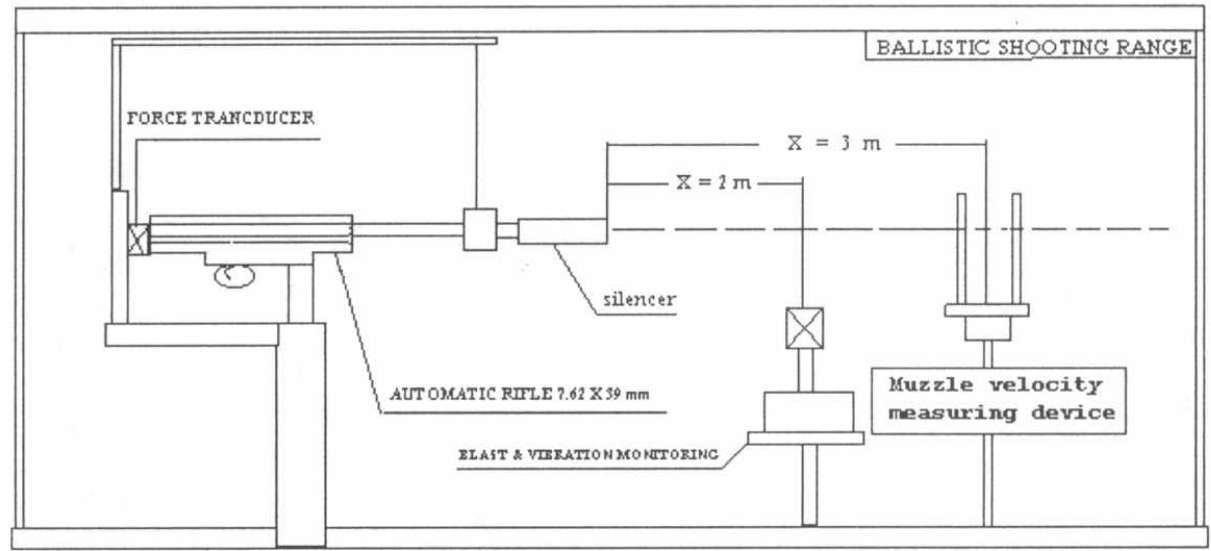

Fig. 1 Schematic of the experimental setup.

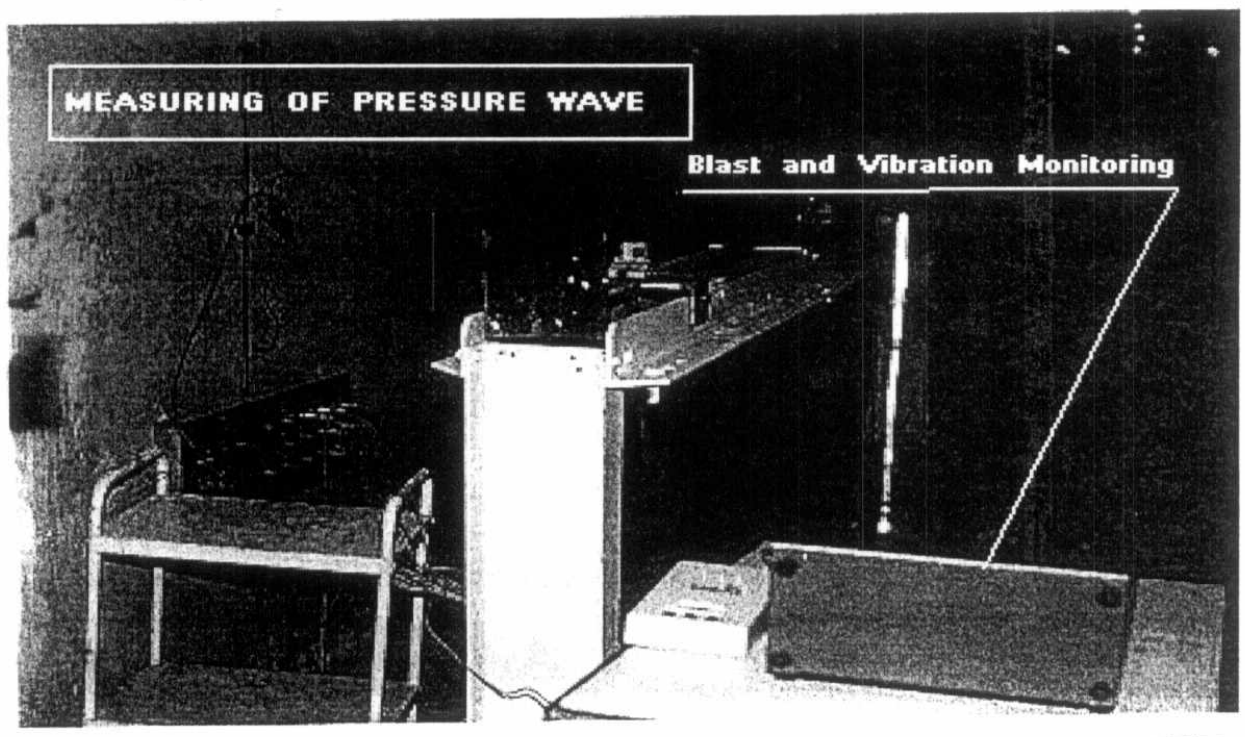

Fig. 2 Photograph for position of Blast and Vibration Monitoring. 


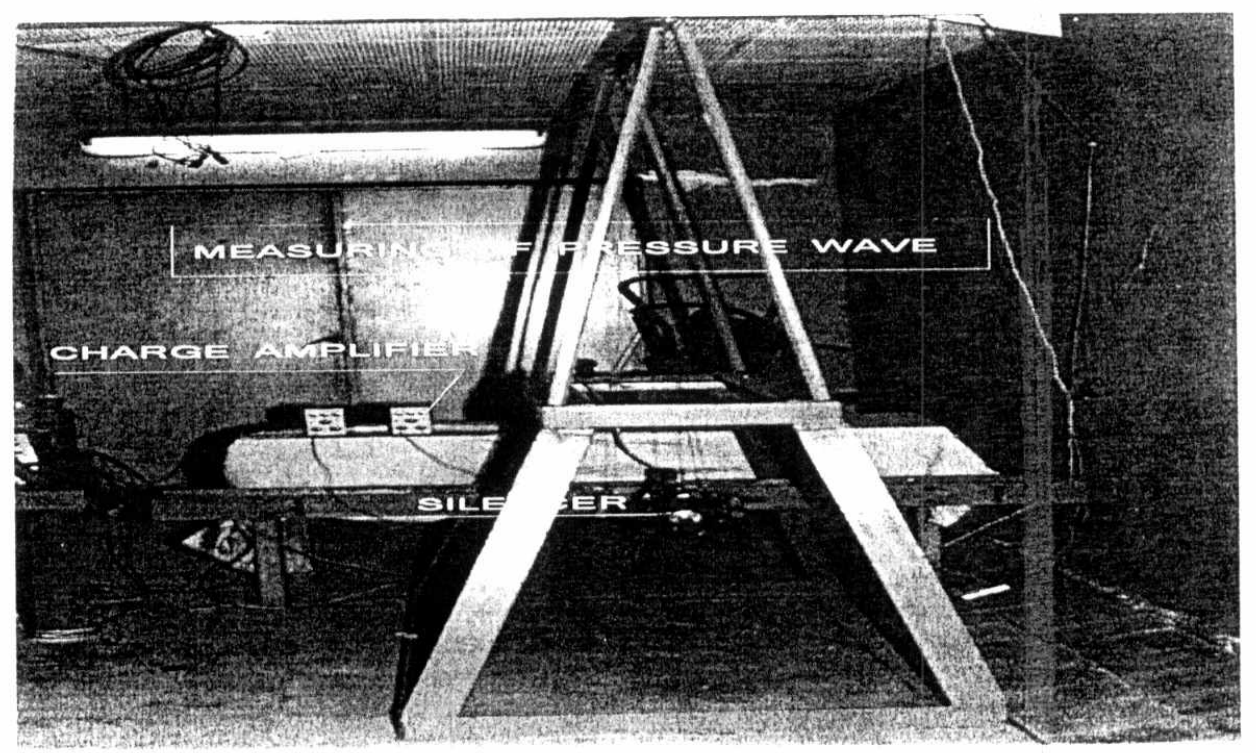

Fig. 3 Photograph for setup of automatic rifle.

Detail $\mathrm{A}-\mathrm{A}$
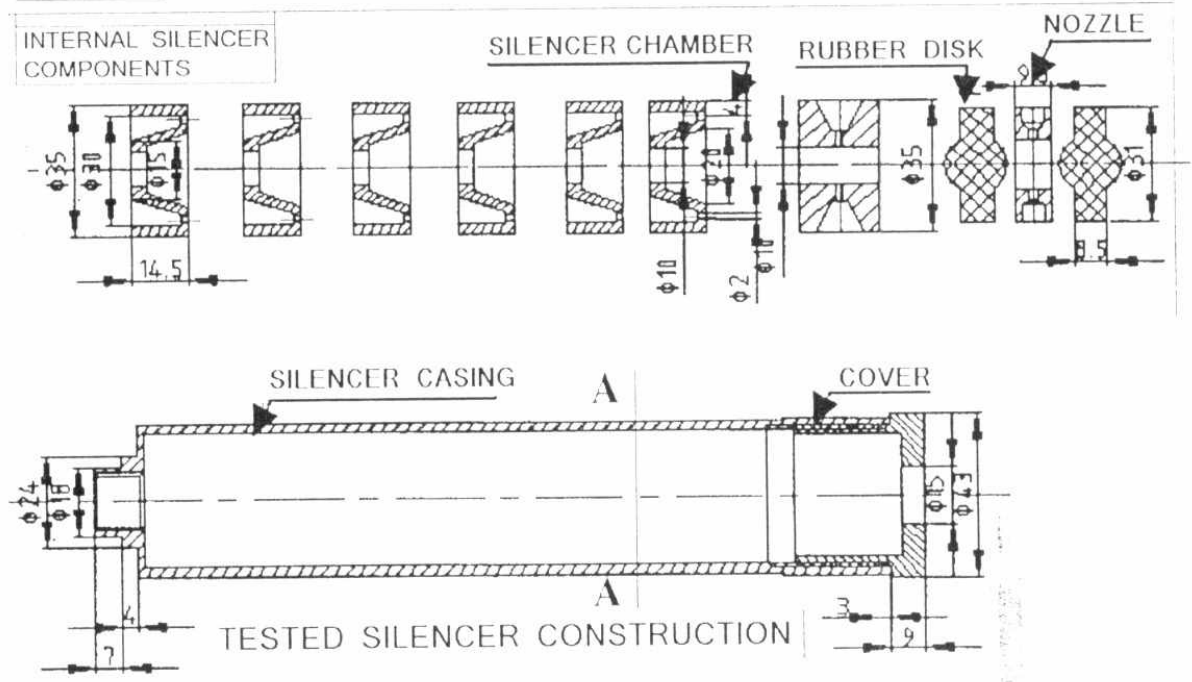

Fig. 4 Construction of the tested silencer. 


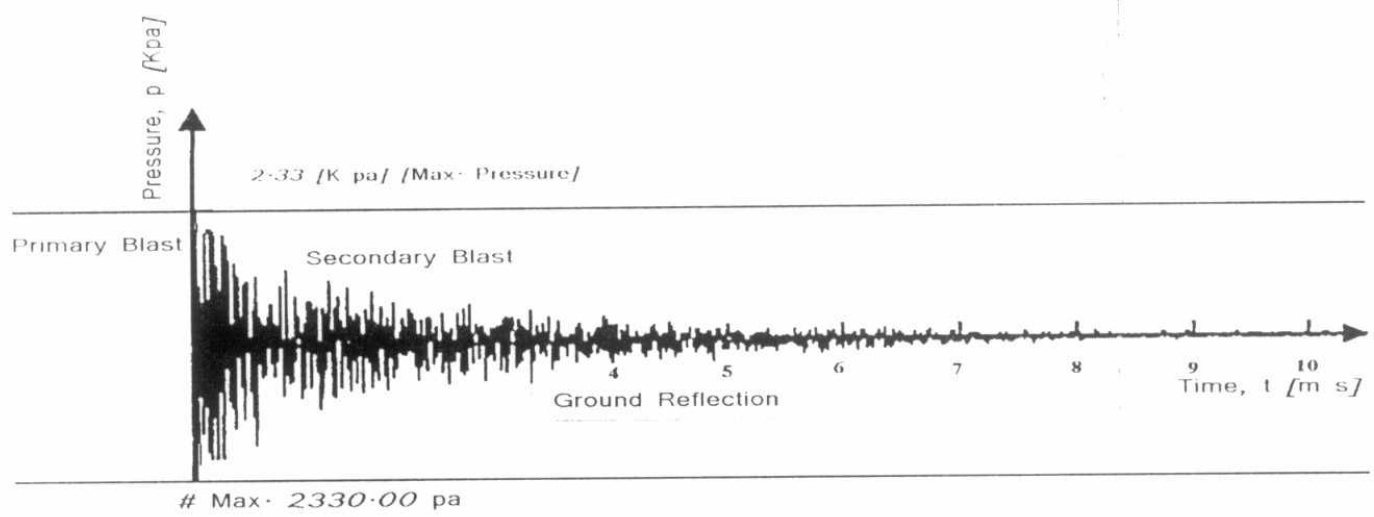

Fig.5 Pressure -time curve measured from the rifle without silencer at propellant charge, $\quad \omega=1.8(\mathrm{gm})$.

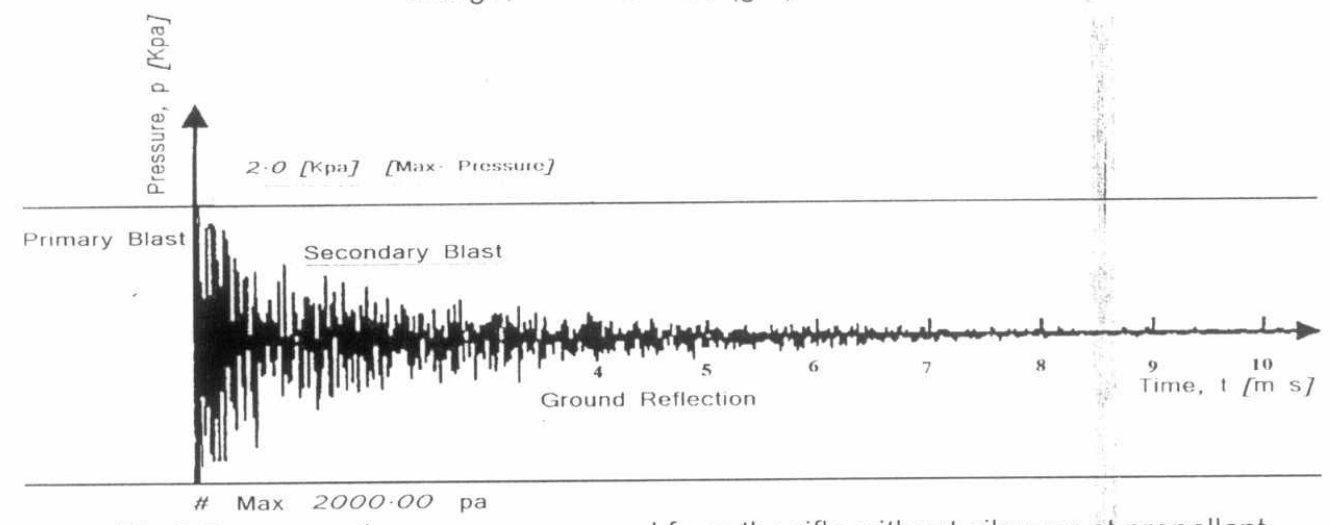

Fig.6 Pressure -time curve measured from the rifle without silencer at propellant charge,

$\omega=1.7$ (gm).

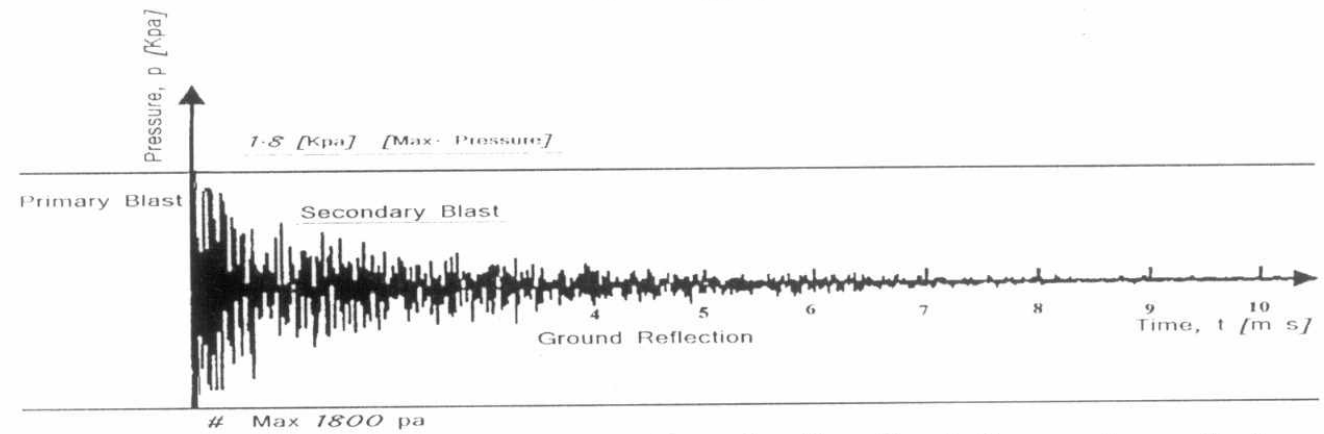

Fig.7 Pressure -time curve measured from the rifle without silencer at propellant 
charge

$$
\omega=1.6(\mathrm{gm})
$$

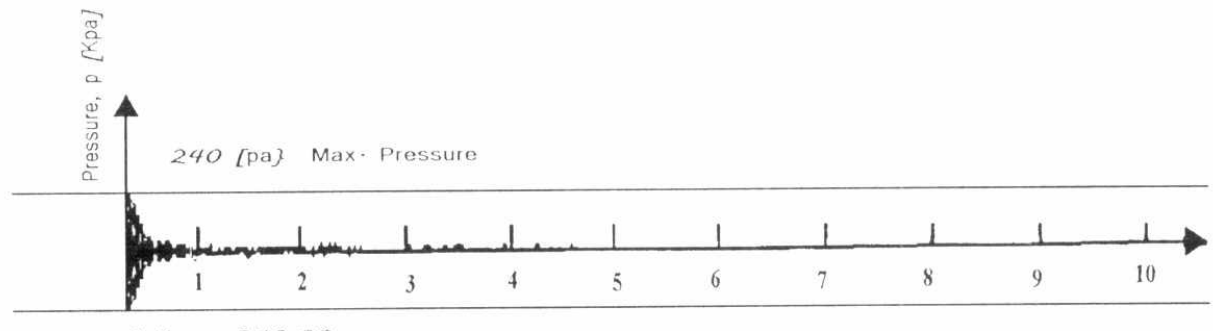

\# Max 240.00 pa

Fig. 8 Pressure -time curve measured from the rifle with silencer at propellant charge, $\omega=1.8$ (gm).

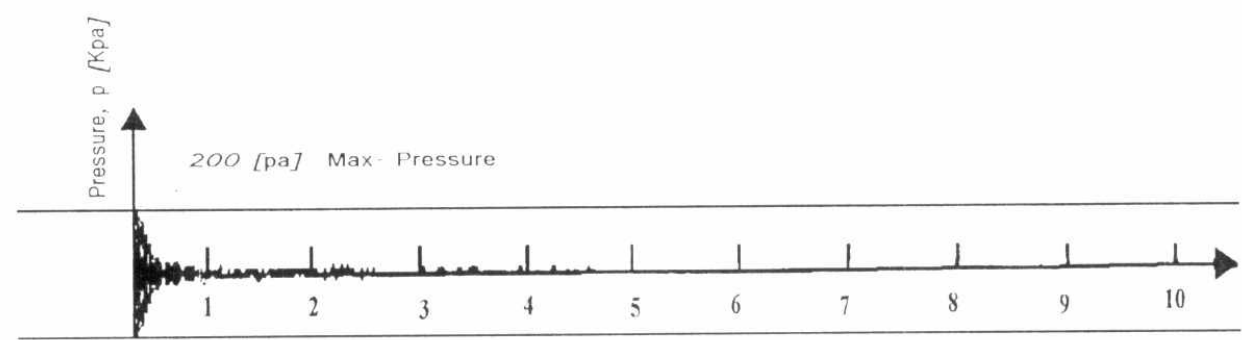

\# $\operatorname{Max} 200.00$ pa

Fig.9 Pressure -time curve measured from the rifle with silencer at propellant charge, $\omega=1.7$ (gm).

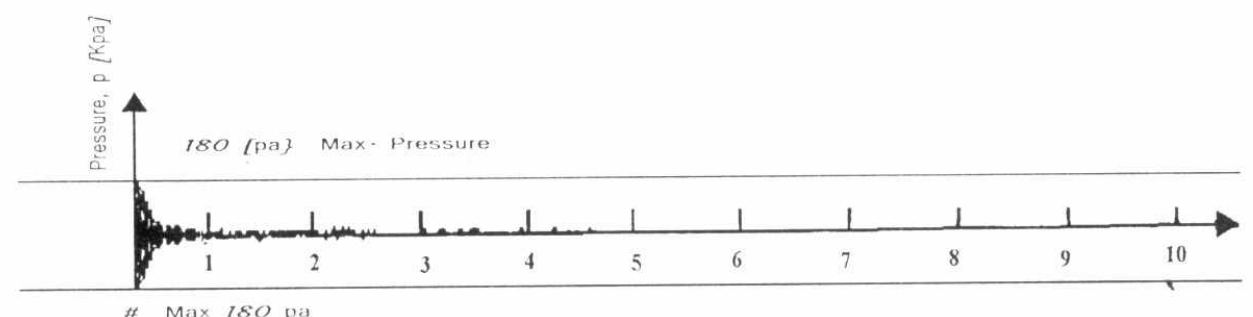

Fig.10 Pressure -time curve measured from the rifle with silencer at propellant charge, 


$$
\omega=1.6 \text { (gm) }
$$

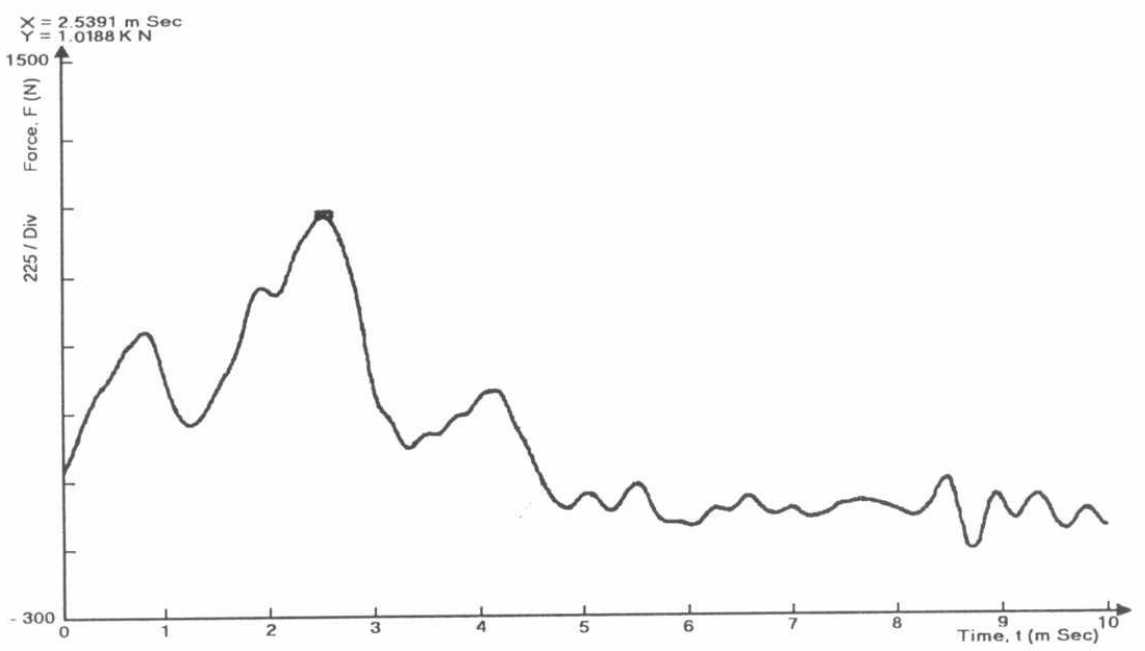

Fig. 11 Recoil force- time history measured for automatic rifle without silencer.

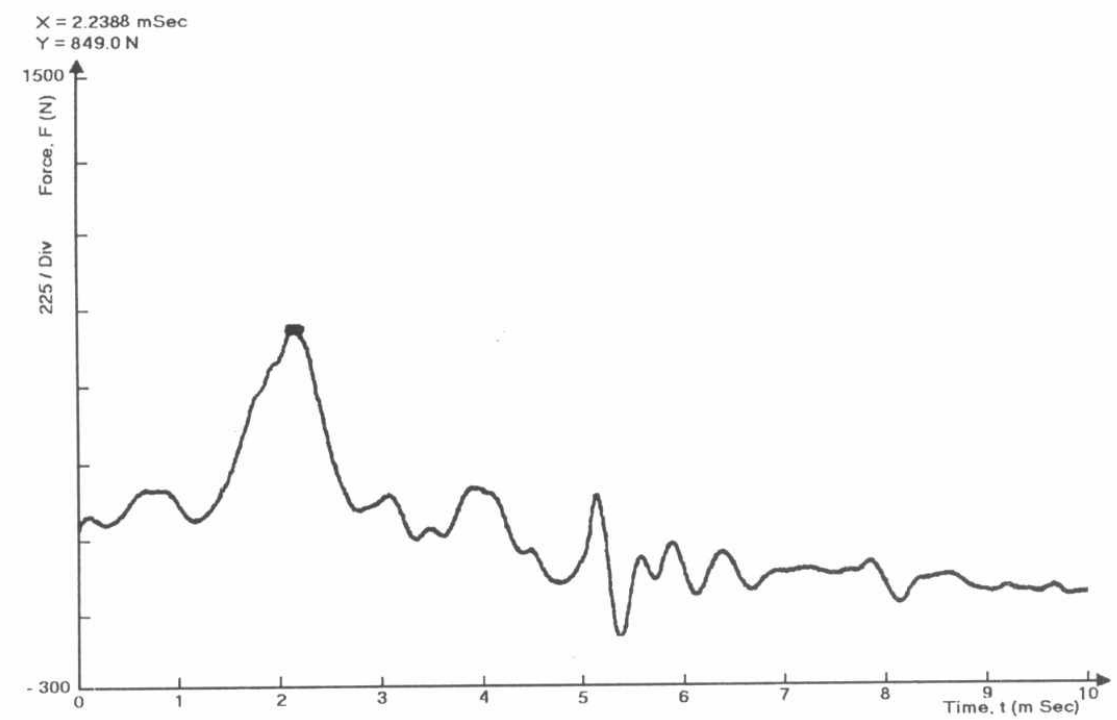

Fig. 12 Recoil force- time history measured for automatic rifle with silencer. 


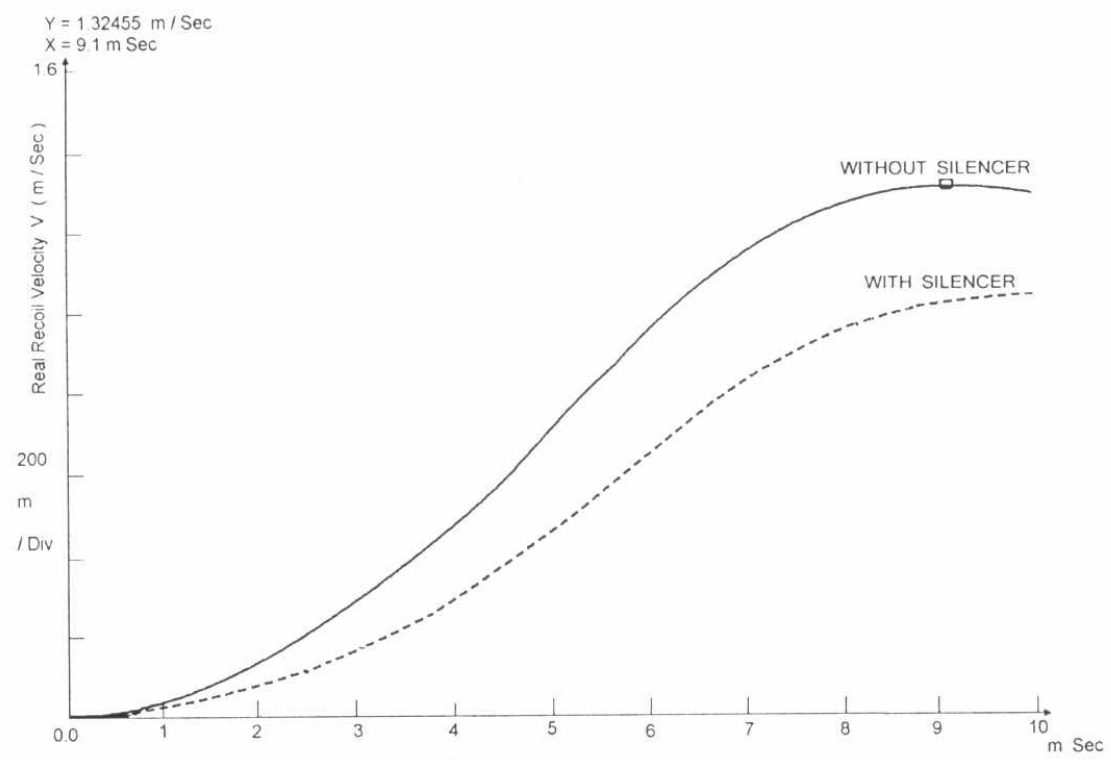

Fig. 13 Comparing between Recoil Velocities measured for Automatic without and with silencer 


\section{CONTENTS}

ST-01 DESIGN OPTIMIZATION OF COMPOSITE ROCKET MOTOR CASES USING GENETIC ALGORITHMS

El-Geuchy, M.I., Zayed, A-N., Wahba W. A., El-Maddah, M.M.

ST-02 EXACT SOLUTION OF ARBITRARILY LAMINATED COMPOSITE BEAMS USING A HIGHER-ORDER THEORY

$$
\text { A. Okasha El-Nady }
$$

ST-03 BALLISTIC RESISTANCE OF FLEXIBLE COMPOSITE (KEVLAR-129/LINE-X XS 350)
A. Fayed, E. Elawad, M. S. Abdelkader

ST-04 ANALYSIS OF TORSION ACTUATION IN ACTIVE THINWALLED SINGLE-CELL COMPOSITE BEAMS

Moustafa Kinawy, Wagdy E. Abdel-Ghany

ST-05 A SUGGESTED NUMERICAL ALGORITHM FOR GEOMETRICALLY NONLINEAR AEROELASTIC BEHAVIOR

Mohammed El-Hadi Ahmed El-Sayed

ST-07 FLUTTER CONSTRAINT FOR AIRCRAFT CONCEPTUAL DESIGN USING RESPONSE SURFACE METHODOLOGY

Ahmed A. Mohamed, Galal B. Salem, Atef M. Hassanein

ST-08 THERMAL DEFORMATION ANALYSIS OF MICROSATELLITE STRUCTURE

Gasser F. Abdelal, Ayman Atef

ST-09 DESIGN, ANALYSIS, AND RELIABILTY OF SOLAR PANEL ROTATION MECHANISM FOR MICROSATELLITE

Gasser F. Abdelal, Mohamed Kassab

ST-10 LIFE PREDICTION MODELING UNDER FATIGUE LOADING FOR ALUMINUM METAL MATRIX COMPOSITES 